\title{
MENINGKATKAN HASIL BELAJAR BAHASA INDONESIA MELALUI MODEL KOOPERATIF STAD UNTUK SISWA KELAS XI MIA4 SMA NEGERI 2 BANGKINANG KOTA TAHUN PELAJARAN 2016/2017
}

\author{
Yurnawilis \\ SMA Negeri 2 Bangkinang Kota, Kabupaten Kampar \\ yurnawilis@gmail.com
}

\begin{abstract}
Classroom action research has been done in SMA Negeri 2 Bangkinang Kota on Indonesian Language subjects with research object of class XI MIA 4 in odd semester 2016/2017. This study was conducted as an effort to improve the learning ability of Indonesian for students of class XI MIA 4. STAD type was chosen to be applied after through observation and reflection conducted by the researcher. Researchers plan actions based on observations and reflections that have been done through the preparation of STAD type learning based learning tools consisting of Cycle I / test questions, and Cycle II test/test, observation sheet and lesson plan and other supporting learning tools. The implementation of STAD type cooperative learning in the learning process through the preparation stage, class presentation, group activities, carry out evaluation, group awards and recalculate basic scores and group changes. This study can be completed in 2 cycles 6 meetings, at meeting 3 and 6 meeting conducted test / repeat and complete recapitulation of learning showed that there has been an increase of positive student learning activity in class and increasing of test mean (repetition) and also increase of classical completeness from cycle I with cycle II. Student activity during the learning process is observed by the observer as data for evaluation and reflection. Average recapitulation of test (repetition) and learning completeness obtained from the value of the test in cycle 1 and the value of tests in cycle 2. Based on the results of research can be concluded that the application of learning with STAD type in class XI MIA 4 SMA Negeri 2 Bangkinang City able to improve learning outcomes subjects Indonesian language is indicated by the average test (repetition) and classical completeness in every cycle.
\end{abstract}

Keywords: STAD type, learning result Indonesian, Test Average (Deuteronomy)

\begin{abstract}
ABSTRAK
Penelitian tindakan kelas telah dilakukan di SMA Negeri 2 Bangkinang Kota pada mata pelajaran Bahasa Indonesia dengan objek penelitian kelas XI MIA 4 pada semester ganjil 2016/2017. Penelitian ini dilakukan sebagai upaya meningkatkan kemampuan belajar Bahasa Indonesia bagi siswa kelas XI MIA 4. Metode STAD dipilih untuk diterapkan setelah melalui observasi dan refleksi yang dilakukan oleh peneliti. Peneliti merencanakan tindakan berdasarkan pengamatan dan refleksi yang telah dilakukan melalui persiapan alat pembelajaran berbasis pembelajaran STAD yang terdiri dari pertanyaan Siklus I / tes, dan tes / tes Siklus II, lembar observasi dan rencana pelajaran serta alat pendukung pembelajaran lainnya. Pelaksanaan pembelajaran kooperatif tipe STAD dalam proses pembelajaran melalui tahap persiapan, presentasi kelas, kegiatan kelompok, melaksanakan evaluasi, penghargaan kelompok dan menghitung kembali skor dasar dan perubahan kelompok. Penelitian ini dapat diselesaikan dalam 2 siklus 6 pertemuan, pada pertemuan 3 dan 6 rapat yang dilakukan tes / ulangan dan rekapitulasi pembelajaran lengkap menunjukkan bahwa telah terjadi peningkatan aktivitas belajar siswa yang positif di kelas dan meningkatnya rata-rata tes (repetisi) dan juga peningkatan kelengkapan klasik dari siklus I dengan siklus II. Aktivitas siswa selama proses pembelajaran diamati oleh pengamat sebagai data untuk evaluasi dan refleksi. Rekapitulasi rata-rata tes (repetisi) dan kelengkapan pembelajaran diperoleh dari nilai tes pada siklus 1 dan nilai tes dalam siklus 2. Berdasarkan hasil penelitian dapat disimpulkan bahwa penerapan pembelajaran dengan tipe STAD di kelas XI MIA 4 SMA Negeri 2 Kota Bangkinang
\end{abstract}


mampu meningkatkan hasil belajar mata pelajaran Bahasa Indonesia ditunjukkan dengan rata-rata ulangan (repetisi) dan ketuntasan klasikal dalam setiap siklusnya.

\section{Kata kunci: tipe STAD, hasil belajar Bahasa Indonesia, Test Average (Ulangan)}

\section{PENDAHULUAN}

Struktur kurikulum merupakan pola dan susunan mata pelajaran yang harus ditempuh oleh peserta didik dalam kegiatan pembelajaran.Kedalaman muatan kurikulum pada setiap mata pelajaran pada setiap satuan pendidikan dituangkan dalam kompetensi yang harus dikuasai peserta didik sesuai dengan beban belajar yang tercantum dalam kurikulum.Kompetensi yang dimaksud terdiri atas kompetensi inti dan kompetensi dasar yang dikembangkan berdasarkan kompetensi lulusan. Pembelajaran Bahasa Indonesia kelasXI MIA 4 SMA Negeri 2 Bangkinang Kota tahun Ajaran 2016/2017 telah sesuai dengan Kurikulum 2013 yang sudah direvisi. Pelaksanaan pembelajaran mata pelajaran Bahasa Indonesia kelas XI MIA 4SMA Negeri 2 Bangkinang Kota sesuai kurikulum berjumlah 4 jam per minggu.

Dalam proses belajar mengajar guru harus memiliki strategi agar siswa dapat belajar secara efektif dan efisien, sesuai tujuan yang diharapkan. Menurut Uzer dalam Depdiknas (2006) mengemukakan bahwa untuk menciptakan kondisi belajar mengajar yang efektif ada lima variabel yang menentukan keberhasilan, yaitu 1) melibatkan siswa secara aktif, 2) menarik minat dan perhatian siswa, 3) mengembangkan motivasi siswa, 4) perbedaan individualitas, 5) peragaan dalam pembelajaran. Peranan guru dalam memilih model pembelajaran sangat menentukan hasil belajar siswa.

Pembelajaran kooperatif telah dikembangkan secara intensif melalui berbagai penelitian, tujuannya untuk meningkatkan kerjasama akademik antar siswa, membentuk hubungan positif, mengembangkan rasa percaya diri, serta meningkatkan kemampuan akademik melalui aktivitas kelompok. Dalam pembelajaran kooperatif terdapat saling ketergantungan positif diantara siswa untuk mencapai tujuan pembelajaran. Setiap siswa mempunyai kesempatan yang sama untuk sukses. Aktivitas belajar siswa berpusat pada siswa dalam bentuk diskusi, mengerjakan tugas bersama, saling membantu dan saling mendukung dalam memecahkan masalah.Melalui interaksi belajar yang efektif siswa lebih termotivasi, percaya diri, mampu menggunakan strategi berpikir tingkat tinggi, serta membangun hubungan interpersonal. Model pembelajaran kooperatif memungkinkan semua siswa dapa menguasai materi pada tingkat penguasaan yang relatif sama.

Belajar merupakan suatu proses kegiatan yang dilakukan agar terjadi suatu perubahan tingkah laku pada seseorang, dari tidak tahu menjadi tahu, dan dari tidak mengerti menjadi mengerti, sebagai akibat dari interaksi seseorang dengan lingkungannya. Perubahan yang terjadi pada diri seseorang tersebut merupakan hasil yang diperoleh melalui proses belajar. Oemar Hamalik (2004: 30) menjelaskan bahwa,"Hasil belajar merupakan bukti terjadinya perubahan tingkah laku seseorang, yang tampak pada aspek-aspek seperti; aspek pengetahuan, pengertian, kebiasaan, keterampilan, apresiasi, emosional, hubungan sosial, jasmani, etis budi pekerti, dan sikap."

Berdasarkan keterangan di atas faktor yang mempengaruhi hasil belajar adalah faktor yang berasal dari dalam diri siswa itu sendiri seperti faktor jasmaniyah dan faktor psikologis yang bersifat bawaan yang berasal dari dalam diri siswa itu sendiri. Dan faktor yang berasal dari luar diri siswa atau faktor eksternal seperti: faktor sosial berupa lingkungan yang ada di sekitar siswa, baik lingkungan keluarga maupun lingkungan sekolah atau lingkungan keluarga yang ada di sekitar siswa. Berdasarkan keterangan di atas faktor yang mempengaruhi hasil belajar adalah faktor yang berasal dari dalam diri siswa itu sendiri seperti faktor jasmaniyah dan faktor psikologis yang bersifat bawaan yang berasal dari dalam diri siswa itu sendiri. Dan faktor yang berasal dari luar diri siswa atau faktor eksternal seperti: faktor sosial berupa lingkungan yang ada di sekitar siswa, baik lingkungan keluarga 
maupun lingkungan sekolah atau lingkungan keluarga yang ada di sekitar siswa.

Berdasarkan hasil observasi pada mata pelajaran Bahasa Indonesia kelas XI MIA 4 tahun Ajaran 2016/2017 ditemukan bahwa hasil belajar siswa pada mata pelajaran tersebut masih rendah. Oleh sebab itu, uji coba penggunaan metode pembelajaran kooperatif tipe STAD pada mata pelajaran Bahasa Indonesia siswa kelasXI MIA 4 SMA Negeri 2 Bangkinang Kota tahun Ajaran 2016/2017sangat diperlukan dengan harapan dapat meningkatkan hasil belajar siswa.

Model pembelajaran kooperatif tipe Student Teams Achievment Division (STAD) dikembangkan oleh Robert E. Slavin dan teman-temannya di Universitas Jhon Hopkin, dan merupakan tipe pembelajaran kooperatif yang paling sederhana.Guru yang menggunakan STAD mengacu kepada belajar kelompok siswa yang menyajikaninformasi akademik kepada siswa menggunakan persentase verbal atau teks.Pembelajaran kooperatif tipe STAD membagi siswa dalam kelompok-kelompok kecil yang terdiri dari 4-5 orangyang bersifat heterogen.Komponen utama tipe STAD adalah persentase kelas, kegiatan kelompok, kuis/tes, pemberian skor individu dan penghargaan kelompok.

Langkah-langkah pembelajaran model kooperatif tipe STAD adalah sebagai berikut. (1) Membentuk kelompok yang anggotanya 5 orang secara heterogen (campuran menurut prestasi, jenis kelamin, suku dll). (2) Guru menyajikan pelajaran. (3) Guru memberi tugas kepada kelompok untuk dikerjakan oleh angota-anggota kelompok. Anggotanya yang sudah mengerti dapat menjelaskan pada anggota lainnya sampai semua anggota dalam kelompok mengerti. (4) Guru meminta kepada masing-masing kelompok untuk mempresentasikan. (5) Guru memberi kuis/pertanyaan kepada seluruh siswa. Pada saat menjawab kuis tidak boleh saling membantu.(6) Memberi evaluasi, dan (7) Kesimpulan.

Berdasarkan masalah diatas dapat diidentifikasikan masalah sebagai berikut. (1) Mata pelajaran Bahasa Indonesia di sekolah kurang diminati siswa karena dianggap menjenuhkan. (2) Cara guru menyampaikan materi banyak ceramah, seharusnya mata pelajaran Bahasa Indonesia lebih banyak diskusi, praktek. (3) Guru kurang mengembangkan metodologi pembelajaran dan (4) penggunaan media pembelajaran yang belum maksimal. Adapun rumusan masalah dalam penelitian ini adalah, "Apakah melalui kooperatif tipe Student Teams Achievement Division (STAD) dapat meningkatkan hasil belajar siswa kelasXI MIA 4 SMA Negeri 2 Bangkinang Kota tahun Ajaran 2016/2017? Tujuan penelitian ini adalah untuk meningkatkan hasil belajar siswa kelasXI MIA 4 SMA Negeri 2 Bangkinang Kota tahun Ajaran 2016/2017 melalui metode STAND. Selanjutnya hasil penelitian ini diharapkan dapat bermanfaat sebagai (1) meningkatkan hasil belajar siswa, (2) meningkatkan kemampuan guru tentang cara pembelajaran, (3) meningkatkan kemampuan menulis dan kepekaan terhadap permasalahan pembelajaran di lingkungan sekolah tempat bertugas.

\section{METODOLOGI PENELITIAN}

Jenis penelitian yang dilakukan oleh penulis adalah Penelitian Tindakan Kelas (PTK). Menurut Kunandar (2011: 13), PTK adalah suatu penelitian tindakan yang dilakukan oleh guru sekaligus peneliti di kelasnya dengan merancang, melaksanakan tindakan, dan merefleksikannya dengan tujuan memperbaiki dan meningkatkan mutu pembelajaran. Ada empat tahap yang dilalui dalam pelaksanaan Penelitian Tindakan Kelas (PTK) pada setiap siklusnya yaitu: perencanaan, pelaksanaan tindakan, pengamatan, dan refleksi. Subjek penelitian ini adalah siswa kelas XI MIA4 SMA Negeri 2 Bangkinang Kota tahun pelajaran 2016/2017. Siswa pada kelas ini terdiri dari 33 siswa. Setting penelitian ini dilakukan pada kelas XI MIA 4 tahun pelajaran 2016 /2017 pada semester ganjil sesuai dengan program tahunan, dan program semester yang direncanakan oleh peneliti selaku guru mata pelajaran. Dalam penelitian ini, ada dua instrumen penelitian, yaitu: (1) Test hasil belajar untuk mengukur daya serap siswa dan ketuntasan belajar siswa). Dalam hal ini instrumen yang digunakan adalah berupa tes/ulangan pada akhir setiap siklus. (2) 
Lembar observasi proses belajarsiswa berupa kedisiplinan siswa, keaktifan siswa, dan kepercayaan diri. (3) Lembar Hasil Kerja Kelompok berupa hasil kerja setiap kelompok siswa berupa kebersihan, kerjasama anggota, ketepatan waktu, dan kesesuaian jawaban. Data yang diperoleh melaluites dilakukan sebanyak dua kali yaitu tes pada siklus I dan tes pada siklus II. Data non tes diperoleh melalui observasi/pengamatan. Analisis data dilakukan dengan teknik rerata presentase skor yang diperoleh siswa. Nilai tes siswa diklasifikasikan untuk menentukan tingkat kemampuan siswa dengan klasifikasi sebagai berikut:

Tingkat Kemampuan

\begin{tabular}{|c|c|}
\hline Klasifikasi & Predikat \\
\hline $91-100$ & Baik Sekali \\
\hline $83-90$ & Baik \\
\hline $75-82$ & Cukup \\
\hline $61-74$ & Kurang \\
\hline $0-60$ & Sangat Kurang \\
\hline
\end{tabular}

\section{HASIL PENELITIAN}

Data hasil pengamatan dan hasil belajar pada penelitian dari siklus I sampai dengan siklus II , yaitu pengamatan proses belajar, pengamatan kerja kelompok, dan hasil belajar dapat dijelaskan pada tabel rekapitulasi pengamatan proses belajar, kerja kelompok, dan hasil belajar dari siklus I s.d. siklus II dapat disajikan sebagai berikut.

Tabel 23.Rekapitulasi Pengamatan Proses Belajar, Kerja Kelompok Dan Hasil Belajar

\begin{tabular}{|c|c|c|c|c|}
\hline No & Uraian & $\begin{array}{l}\text { S. I } \\
\text { P. } 1 \% \\
\end{array}$ & $\begin{array}{l}\text { S. I } \\
\text { P. } 2 \% \\
\end{array}$ & $\begin{array}{l}\text { S. I } \\
\text { P. } 3 \% \\
\end{array}$ \\
\hline \multirow{3}{*}{1} & \multirow{3}{*}{$\begin{array}{l}\text { Proses } \\
\text { belajar }\end{array}$} & $A=30,30 \%$ & $A=0 \%$ & - \\
\hline & & $B=35,35 \%$ & $\mathrm{~B}=51,67 \%$ & - \\
\hline & & $\mathrm{C}=34,34 \%$ & $\mathrm{C}=48,33 \%$ & - \\
\hline \multirow{3}{*}{2} & \multirow{3}{*}{$\begin{array}{l}\text { Kerja } \\
\text { kelompok }\end{array}$} & $A=32,14 \%$ & $\mathrm{~A}=0 \%$ & - \\
\hline & & $\mathrm{B}=35,71 \%$ & $\mathrm{~B}=55 \%$ & - \\
\hline & & $\mathrm{C}=32,14 \%$ & $\mathrm{C}=45 \%$ & - \\
\hline \multirow[b]{2}{*}{3} & \multirow[b]{2}{*}{$\begin{array}{l}\text { Hasil } \\
\text { belajar }\end{array}$} & - & - & $\mathrm{T}=66,67 \%$ \\
\hline & & - & - & $\mathrm{TT}=33,33 \%$ \\
\hline
\end{tabular}

Keterangan: S: siklus, P: pertemuan, A: amat baik, B: baik, C: cukup, T: tuntas, TT: tidak tuntas

\begin{tabular}{|c|c|c|c|c|}
\hline No & Uraian & $\begin{array}{l}\text { S. II } \\
\text { P. } 4 \%\end{array}$ & \begin{tabular}{|l|} 
S. II \\
P.5\%
\end{tabular} & $\begin{array}{l}\text { S. II } \\
\text { P. } 6 \%\end{array}$ \\
\hline \multirow{3}{*}{1} & \multirow{3}{*}{$\begin{array}{l}\text { Proses } \\
\text { belajar }\end{array}$} & $\mathrm{A}=30,30 \%$ & $A=34,34 \%$ & - \\
\hline & & $B=50,51 \%$ & $\mathrm{~B}=54,53 \%$ & - \\
\hline & & $\mathrm{C}=19,19 \%$ & $\mathrm{C}=13,13 \%$ & - \\
\hline \multirow{3}{*}{2} & \multirow{3}{*}{$\begin{array}{l}\text { Kerja } \\
\text { kelompok }\end{array}$} & $\mathrm{A}=28,57 \%$ & $A=35,71 \%$ & - \\
\hline & & $\mathrm{B}=50 \%$ & $B=57,14 \%$ & - \\
\hline & & $\mathrm{C}=21,43 \%$ & $\mathrm{C}=7,14 \%$ & - \\
\hline \multirow[b]{2}{*}{3} & \multirow[b]{2}{*}{$\begin{array}{l}\text { Hasil } \\
\text { belajar }\end{array}$} & 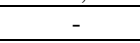 & - & $\mathrm{T}=87,88 \%$ \\
\hline & & - & - & $\mathrm{TT}=13,13 \%$ \\
\hline
\end{tabular}

Berdasarkan tabel di atas dapat dijelaskan sebagai berikut.

1. Pengamatan proses belajar pada pertemuan pertama ditemukan aspek kedisiplinan siswa dalam belajar sangat kurang. Siswa banyak yang tidak membuat PR, tidak membawa alat/buku, dan ada yang terlambat datang ke sekolah. Siswa hanya diam mendengarkan penjelasan guru. Pada hasil kerja kelompok ditemukan aspek kebersihan masih perlu mendapat perhatian. Pekerjaan kelompok masih kotor banyak coretan. Pada pertemuan berikutnya guru memperbaiki pembelajaran terutama pada aspek-aspek tersebut.

2. Pertemuan ke-2 aspek kepercayaan diri masih kurang, siswa kurang percaya dengan kemampuan sendiri, banyak siswa masih percaya dengan kawannya yang belum tentu betul jawabannya. Aspek ini pada pertemuan ke-4 perlu mendapat perhatian.

3. Pada penilaian hasil belajar pada pertemuan ke-3, siswa yang mencapai nilai di atas KBM masih di bawah $75 \%$. Pada pertemuan berikutnya guru lebih memperhatikan dan mengarahkan siswa dalam menjawab soal tes/ulangan.

4. Pada pertemuan ke-4 perbaikan yang akan dilakukan pada pertemuan berikutnya adalah aspek keaktifan siswa dalam belajar. Siswa kurang aktif, cendrung duduk diam mendengar penjelasan guru atau penjelasan kawannya. Guru harus memotivasi siswa dalam belajar terutama dalam menanggapi pertanyaan atau jawaban kawannya. 
Pada hasil kerja kelompok pada pertemuan ke-4 yang perlu diperbaiki pada pertemuan berikutnya adalah aspek kesesuaian jawaban.Hal ini terlihat masih ada beberapa kelompok yang tugas kelompoknya tidak sesuai jawaban dengan perintah tugasnya.

5. Pada pertemuan ke-5 Pengamatan proses belajar yang perlu diperbaiki adalah aspek pemahaman materi. Pada pertemuan berikutnya guru lebih meningkatkan cara pembelajaran agar pemahaman siswa terhadap materi pelajaran meningkat. Aspek kesesuaian jawaban pada hasil kerja kelompok masih perlu mendapat perhatian.

6. Pertemuan ke-6 terlihat bahwa hasil belajar sudah terdapat peningkatan, hal ini terlihat dari ketuntasan belajar juga meningkat yaitu siswa yang tuntas = $87,88 \%$ dan yang tidak tuntas $13,13 \%$.

\section{SIMPULAN}

Berdasarkan hasil rekapitulasi data pangamatan dan hasil belajar siswa, dapat disimpulkan sebagai berikut. (1) Pada pengamatan proses belajar dari pertemuan pertama sampai dengan pertemuan ke-6 terdapat peningkatan aktivitas siswa dalam belajar. Hal ini terjadi setelah ada perbaikan pembelajaran yang dilakukan guru pada setiap pertemuan. (2) Penilaian hasil belajar terjadi peningkatan penguasaan materi oleh siswa yaitu pada siklus pertama siswa yang dinyatakan tuntas $66,67 \%$,tidak tuntas $33,35 \%$, pada siklus kedua siswa yang dinyatakan tuntas $87,88 \%$ dan yang tidak tuntas $13,13 \%$ Jadi, secara keseluruhan terdapat peningkatan hasil belajar siswa .

\section{REFERENSI}

Depdiknas.2006. Kegiatan Belajar mengajar yang Efektif.Jakarta : Puskur Balitbang depdiknas.

Departemen Pendidikan Nasional. 2008. Peraturan Mentri Pendidikan Nasional No 22 Tahun 2006 Tentang Standar Isi. Jakarta: Depdiknas.

Djamarah, Syaiful Bahri, 2005. Guru dan Anak Didik Dalam Interaksi
Edukatif,Suatu Pendekatan Teoritis Psikologis,Jakarta ,Penerbit PT Rineka Cipta.

Gulo,W. 2002. Strategi Belajar

Mengajar,Jakarta,Penerbit PT Gramedia Widiasarana Indonesia.

Hadi, Sutrisno. 1986. Metodologi Reseach,Yogyakarta,Yayasan Penerbit Fakultas Psikologi Universitas Gajah Mada.

Hamalik,Oemar, 1983. Metode Belajar dan Kesulitan Belajar ,Bandung,Penerbit Tarsito.

Nazir,Mohammad.1985. Metode Penelitian Survai,Jakarta,Penerbit Lembaga Penelitian Pendidikan dan Penerangan Rinderiyana, Aidin Adlan. 2011. Bimbingan Praktis Penelitian Tindakan Kelas. Kudus: Dita Kurnia. 